\title{
SARTRE EN LA FILOSOFÍA DE DELEUZEY Y FOUCAULT
}

\author{
Eduardo Alberto León* \\ Instituto Ilven-Charlotte Quito, Ecuador
}

\section{Resumen}

Sartre en la filosofía de Deleuze y Foucault. Las relaciones entre las filosofías de Sartre y la generación siguiente estuvieron marcadas por el conflicto. Tomando como referencias los proyectos de Foucault y Deleuze, se intentará mostrar hasta qué punto existe una relación entre estas filosofías posmodernas y algunas propuestas sartreanas, especialmente las que están más cercanas a Nietzsche esencialmente las primeras obras de Sartre que abundan en la noción de proyecto como constituyente de la actitud ética, y desde luego, las que operan a partir de la renuncia a la idea de totalidad hegeliano-marxista.

Palabras clave: Sartre. Deleuze. Foucault. Inquietud de sí. Ética

\begin{abstract}
Sartre: on the Philosophy of Deleuze and Foucault. The relationships between Sartre's philosophies and the following generation were marked by conflict. In reference to the projects of Foucault and Deleuze, this article will attempt to demonstrate the extent to which the relationship between these postmodern philosophies and Sartre's philosophies exists. It will focus on those philosophies closest to the early works of Nietzsche and Sartre, especially those that thrive on the notion of project as a constituent of ethical attitude, and, of course, those that operate on the renunciation of the Hegelian-Marxist idea of totality.
\end{abstract}

Key words: Sartre, Deleuze, Foucault, Self-inquiry, Ethics.

*alberto3026@yahoo.es 


\section{Introducción: un extraño malentendido}

Antes de hablar específicamente de la presencia de Sartre en Deleuze y Foucault, es necesario subrayar la irrupción de la fenomenología husserliana. El autor de las Investigaciones lógicas visitó la Sorbonne en febrero de 1929. Por entonces ya estaba centrado en la redacción de las Meditaciones cartesianas. Su obra había dado un giro notable si tenemos en cuenta lo advertido en el prólogo a la segunda edición de las "Investigaciones", así como la aceptación anunciada al comienzo de la Sección segunda de las Ideas donde se entiende el mundo no sólo como "un mero mundo de cosas... sino, en la misma forma inmediata, como un mundo de valores y de bienes, un mundo práctico" (Husserl;1949: 66) $\mathrm{y}$, obviamente, el giro espectacular que ya se revela en la primera de las Meditaciones cartesianas cuando se anuncia el proyecto de referirse a un yo psicológico y a un yo trascendental. En las páginas de la quinta meditación se apela a una intersubjetividad trascendental, presuponiéndose un común trasfondo eidético al yo psicológico. La conciencia es intencional, pero es algo más que eso al estar establecida por la comunidad intencional con un existente concreto.

Algunos intérpretes husserlianos en Francia no reciben escandalizados el giro fenomenológico. Lévinas, quien publica en 1930 La Théorie de la intuition dans la phénoménologie de Husserl, señalará que el yo trascendental es articulable con el yo psíquico y que la radical intencionalidad de la conciencia no es menoscabada por tal duplicación. Pero no es ésta la actitud de Sartre, quien redactará varios artículos a propósito del desvío husserliano. Es cierto que Sartre había quedado seducido por el proyecto fenomenológico como Simone de Beauvoir ha memorializado el suceso. Sin embargo, resulta difícil de aceptar que Sartre esté en condiciones de asumir el giro fenomenológico que culmina en la duplicación del yo y, de hecho, su operación polémica estará orientada por el interés de salvar la fenomenología como filosofía sin duplicidades metodológicas. Es cierto, como recuerda Cohen Solal, que "hasta 1939, en el dominio filosófico, leerá exclusivamente a Husserl" ( Cohen-Solal;1985:139), pero es igualmente incontestable, como ha subrayado con oportunidad V. de Coorebeyter, que Sartre vive diez años "escribiendo bajo la inspiración de Husserl, pero a un tiempo contra él". El diagnóstico sartreano será sumamente severo. En el artículo más conocido del grupo que integran sus trabajos contra Husserl - La trascendencia del Ego, publicado en el número 6 de las Recherches philosophiques (19361937) - sostendrá que la duplicación egológica es una infidelidad al carácter esencialmente intencional de la conciencia. Pero es "por desgracia, la orientación 
del nuevo pensamiento de Husserl" Y continúa: "la conciencia se ha vuelto más pesada, ha perdido ese carácter que hacía de ella el existente absoluto a fuerza de inexistencia. Es pesada y ponderable. Todos los resultados de la fenomenología entonces quedarían arruinados si el Yo mismo no es, al mismo título que el mundo, un existente relativo, es decir, un objeto para la conciencia" (Sartre: 1968: 22. ). Se impone el retorno fenomenológico a la conciencia vacía que se configura en la apertura al mundo para iniciar el peligroso juego de la existencia. La quiebra con todo contenido trascendente, efecto del reconocimiento de la muerte de Dios y de la exigencia de hacer irreductible el sujeto, determinará la inmediata proyección sartreana: es la claridad teórica que alimenta las páginas de La náusea y de Lo imaginario.

La segunda presencia es Hegel... Pocos años después de la visita parisina de Husserl, inicia Kojève su seminario sobre la filosofía religiosa de Hegel. Sartre conoce con toda seguridad el contenido de sus lecciones, pues se refiere taxativamente a la orientación de los cursos en los póstumos Cahiers pour une morale. El fermento germinará y, así, J. Hyppolite publica en 1939-1941 la primera traducción de la Fenomenología del Espíritu y años más tarde su fundamental estudio sobre Hegel — Génesis y estructura de la Fenomenología del espírituiniciado en 1946. Ahora bien, ¿qué condiciona la lectura kojeviana? Chiodi y Boschetti han remarcado el carácter de la lectura existencialista que trasmite el texto kojeviano a partir de la traducción de la Fenomenología del Espíritu, y años más tarde, su fundamental estudio sobre Hegel: La dialéctica del amo y del esclavo en Hegel. Ya lo había subrayado tempranamente Canguilhem al apuntar que Kojéve dijo que "la vida es humana y la memoria es el proyecto". (G. Canguilhem: 1991;24)En efecto, acaso baste trascribir un fragmento para percibir el sentido y alcance de tal apreciación. Escribe Kojève:

Ahora bien, ¿qué es el Deseo — no hay que pensar en el deseo llamado hambresino el deseo de trasformar por una acción, la cosa contemplada, suprimirla en su ser que carece de relación con lo mío, que es independiente de mí, negarla en esa su independencia, y asimilármela, hacerla mía, absorberla en y por mi Yo? Para que haya Autoconciencia, y por consiguiente filosofía, es necesario por tanto que haya en el Hombre, no solamente contemplación positiva, pasiva, única reveladora del ser, sino aún Deseo negador, y por consiguiente Acción transformadora del ser dado. Es necesario que el Yo humano sea un Yo del deseo, es decir un Yo activo, un Yo negador que transforma el Ser, que crea un ser nuevo destruyendo el ser dado". ( G. Canguilhem, en Magazine littéraire, $\mathrm{n}^{\circ}$ 293, noviembre de 1991: 29). 
La lección es de indudable relevancia: se procede a un análisis del Deseo (Begierde) hegeliano que se traduce como magnificación de la proyección humana y como consecuente indicación del carácter conflictivo de la misma, ámbito exclusivo de la ejemplaridad dialéctica.

No es de extrañar que tal interpretación seduzca a Sartre, quien asumirá la doble orientación del seminario kojeviano. De dicho acuerdo quedan testimonios en los "Cahiers". De forma explícita, comentado a Kojève, escribe: "entiende bien que la historia implica la libertad: evolución creadora, es decir, materialización de un porvenir que no es la simple prolongación del pasado en el presente. El pasado es la situación, contraída y superada por la acción libre" ( Kojève: 1971; 190). Por la perspectiva histórica se acentúa el rechazo de cualquier posibilidad de síntesis intersubjetiva.

Es en las páginas del póstumo Sartre, él se refiere al mythe hégélien y al universal como suplantación de identidad existencial (la realidad virtual sacrificada) y como la alienación. La denuncia de la mistificación hegeliana de un sentido de libertad es igualmente severa que la crítica a la egología trascendental husserliana. La obra hegeliana ha irrumpido, pero, como observara Kojève, Hegel ha muerto aunque sobreviva la dialéctica - una dialéctica que es preciso reinterpretar desde la perspectiva de lo humano. El posicionamiento es indudable. Aparece como inadmisible la pretensión de la dialéctica hegeliana: la aventura limitada por el Ser y el Deber ser. En Sartre la dialéctica es atravesada por el Deseo al que le resulta impertinente toda referencia que se sitúe más allá de la íntima satisfacción del sujeto, del existente irreductible, quien se presenta como el negador de la inmediatez constitutiva que será conceptualizado en El ser y la nada como situación-proyecto.

El desplazamiento sartreano en relación al sistema hegeliano determina la aproximación existencialista al materialismo histórico. Desde luego, la presencia de Marx en Francia no tiene equivalencia con las novedades husserliana y hegeliana a las que nos hemos referido. Se trata de una presencia ya establecida ${ }^{1}$.

1 La bibliografía al respecto es abundante. Aproximaciones al contexto y a las producciones de origen marxista, entre otras, son J-F. Sirinelli, Intellectuels et passions françaises, Paris, Fayard, 1990, y A. Chebel d’Appollonia, Histoire politique des intellectuels en France, $2 v$, Paris, Complexe, 1991. Más restringidamente — aunque ampliando el horizonte cronológico hasta el post-68 (Glucksmann, Levy) — la cuestión es abordada en C. Pianciola, Filosofia e política nel pensiero francese del dopoguerra, Torino, Loescher, 1979. 
El encuentro sartreano será igualmente conflictivo, como lo expone Lukács cuando redacta, en abril de 1960, una nota introductoria para la segunda edición de ¿Existentialisme ou marxisme?.

En los escritos de la época, en efecto, Sartre está empeñado en la exigencia de expulsar a Engels del panteón marxista, discrepando fuertemente de que era posible proclamar la existencia de una dialéctica de la naturaleza, así como la dialéctica (kojeviana) se circunscribe en el horizonte de la praxis humana. La perspectiva no se oscurecerá y tal empeño quedará reafirmado, como es sabido, en las páginas de la Crítica a la razón dialéctica donde podemos leer que "la originalidad de Marx es establecer irrefutablemente contra Hegel que la Historia está en curso, que el ser se mantiene irreductible al Saber, y a la vez, el querer conservar el movimiento dialéctico en el ser y en el Saber" (Sartre:1987; 155). Tal supuesta originalidad o sugerencia animará la aventura intelectual de Sartre entre 1946 y 1960. La dialéctica de lo humano opera en un espacio circunscrito con claridad. Ya había quedado anunciado en los "Cahiers": la libertad «est synthèse dialectique de l'indetermination subjective et de la necessité objetive». No importa para nuestro propósito que la ejecución de tal síntesis esté marcada por el teleologismo o la aletoriedad. Lo esencial — ahora - es subrayar que la recepción sartreana del materialismo histórico pretende conjugar el episodio caracterizado por los factores constitutivos de la situación, que - ciertamenteno refieren inicialmente elementos de comunitariedad social, aunque no los excluya, pues la apertura de la situación sartreana facilita, por ejemplo, el horizonte económico-cultural de la "Crítica" y la dimensión de la proyección libre del individuo irreductible que convierte su existencia en un episodio incomparable, es decir, en una obra de arte —original, irreproducible—.

La red que constituye el subsuelo teórico de Sartre parece conformado. Resulta difícil comprender el malentendido que se producirá si tenemos en cuenta algunos aspectos que se han subrayado: ruptura con la aceptación de todo referente trascendente a la conciencia, reducción del episodio dialéctico al mundo del sentido humano, estudio de la conflictividad necesaria y precisa entre lo objetivo en sí y el para-sí, es decir, la potencia constituyente de la intencionalidad cognoscitiva-imaginativa de la conciencia. En tal conflicto, la proyección del Deseo que, en tanto tal, se manifiesta como quiebra del Ser: es el reto que interminablemente reasumirá la aventura sartreana. Esta tesis ha quedado expresada con claridad en la necesidad de pensar el juego entre la indetermination subjetive y la necessité objetive. Y, sin embargo, es preciso introducir la cuarta 
presencia que Sartre ha incorporado a su interés intelectual -filosófico y literario- . Tal referencia nos ayuda a avanzar. Incuestionablemente, siempre nos encontramos con Nietzsche. ¿También en Sartre?

Es fundamental comentar algo a propósito, puesto que el acontecimiento filosófico que heredará el privilegio del existencialismo reverencia a Nietzsche. Deleuze, por ejemplo. Y Foucault, quien reconocerá en 1980 que Nietzsche, Blanchot y Bataille son los autores que le permitieron liberarse de lo que han dominado mi formación universitaria de los primeros años. Foucault confesará más tarde: Nietzsche fue una revelación para mí. Así, situándonos en una panorámica limitada por el subsuelo teórico sartreano y las invocaciones de los post-sartreanos, podría concluirse que una insalvable distancia se confirma. Y, sin embargo, el propio Foucault nos aconseja considerar la presencia nietzscheana en Sartre cuando recuerde en 1983, subrayando la inversión de los caminos respectivos del propio Sartre y de la generación siguiente, se abordaba en sus páginas el problema de la producción de la verdad.

Una magnífica aproximación a la introducción nietzscheana en Francia ha sido llevada a cabo por J. Le Rider. " La siembra está realizada: el conocimiento de los póstumos ha puesto de relieve la aproximación sartreana a Nietzsche. Ahora bien, ¿qué le llamará la atención a Sartre? Si rastreamos en textos de juventud o en rememoraciones de tales años, no cabe lugar al engaño: la incorporación nietzscheana parece estar limitada por la consideración de la verdad como producción social y por la aceptación de una moral marcada por la proyección individualista que reniega de la actualidad, de la situación. El primer aspecto es ilustrado en la novela juvenil ya citada y el segundo aspecto es subrayado por el propio Sartre en el prólogo a una tardía edición de Aden Arabia, la novela de Paul Nizan. "A los dieciséis años me propuso ser un superhombre y acepté gustoso, escribirá Sartre en ese texto patético y sutil, sólo comparable en cuanto a belleza literaria y precisión a Las palabras". ( Cfr. J. Le Rider, «Les premières lectures françaises», en Magazine littéraire, Hors série 3, pp. 91-94.). Está claro que la configuración de la verdad como efecto socio-cultural y asentamiento de una moral individualista alimentada por la negación de la actualidad, de lo circundante al existente, son las evidencias de una contaminación de notables repercusiones filosóficas.

La constitución de la red teórica que hemos diseñado brevemente determina la fortísima presencia del existencialismo sartreano entre comienzos de la década 
de los años 40 y comienzos de la década de los 60, pero, a un tiempo, llama la atención sobre lo que se deduce como un fuerte malentendido, esto es, el extraño alejamiento de los estructuralistas en relación a Sartre (Sartre:1986;17). Es incuestionable que se asiste, en los años sesenta, a una alteración de la hegemonía en el campo filosófico. Bernard Pingaud sintetizó en las tres páginas los cambios sobresalientes que se producen y los expuso en el número monográfico dedicado a Sartre por la revista $L^{\prime} A r c$. A su vez, Dosse inicia su monumental obra sobre la Historia del estructuralismo reconociendo que "para triunfar, el estructuralismo debía, como en toda tragedia, matar. Ahora bien, la figura tutelar de los intelectuales de la posguerra era J.-P. Sartre" (Dosse: 2004;10). Célebres encontronazos con Althusser, alejamiento de Barthes, inicialmente sartreano... Y el mayor y más sonoro enfrentamiento es el que provoca Lévi-Strauss, quien dedica un semestre en 1961 dentro los seminarios que imparte en la Ècole Pratique des Hautes Ètudes al análisis de la reciente obra sartreana e introducirá un capítulo crítico en El pensamiento salvaje. Entre otros aspectos subrayados por el antropólogo, el punto de desencuentro radica en el hecho de que, a su juicio, Sartre recurre a ejemplaridades de segunda categoría para ilustrar el movimiento que descubre la razón dialéctica lo que siembra el desconcierto en relación a su valoración de las estructuras fuertes — parentesco o lenguaje, por ejemplo-. ¿Y Sartre? Responderá pronto en L'Arc: "No soy hostil al estructuralismo" (Dosse: 2004;12). Pero, a decir verdad, el artículo anuncia esa revancha de J.-P. Sartre a la que se ha referido F. Dosse y que resplandecerá a partir de mayo del 68. Oposición a Foucault: según Sartre, se encuentra una referencia en Las palabras y las cosas:

...una referencia a las sucesivas capas que componen nuestro suelo, «marginando» lo que sería más interesante saber cómo cada pensamiento se construye a partir de estas condiciones, o cómo la gente se mueve de un pensamiento a otro. Se requeriría la intervención de la praxis, es la historia, y es precisamente la profundidad. Razón similares del alejamiento del estructuralismo de Lévi-Strauss, pero, tal como es concebido y practicado por Lévi-Strauss, ha contribuido mucho para desacreditar a la corriente de la historia, en la medida en que se aplica a los sistemas de ya establecidos, tales mitos. (J.-P. Sartre, Sartre répond, L'Arc, nº 30, p. 88).

Ahora bien, ¿es tan marcado el desencuentro? ¿Es estricto concluir que Sartre desconoce la función de las estructuras — denominadas de tal forma o con términos análogos o próximos - y que, paralelamente, los estructuralistas marginan la posibilidad de una subjetividad constituyente que está en condiciones de esquivar la densidad implacable de las estructuras? ¿Es posible concluir que 
la variante inmediata, el postestructuralismo, se acomode sobre las cenizas del pensamiento sartreano aventadas por Lévi-Strauss o Foucault? Colombel ha advertido que por tanto, debemos « abandonar la idea de que Foucault sería un estructuralista con exclusión del sujeto" (J. Colombel, «Sartre et Foucault», en Magazine littéraire, no 384, abril 2000, p. 50). También Schmid en su obra En Busca de un nuevo arte de vivir ha remarcado oportunamente, indudables puntos de contacto entre ellos. Deleuze, el segundo invitado a este encuentro, introduce un afable comentario en Diálogos que va más allá del mero saludo de reconocimiento. Refiriéndose al caduco ambiente filosófico de su juventud, rememora:

Por suerte existía Sartre. Y Sartre era nuestro Exterior, una verdadera corriente de aire fresco... Entre todas las probabilidades de la Sorbona, él era la única combinación capaz de darnos la fuerza necesaria para soportar la nueva reordenación. Y Sartre nunca ha dejado de ser eso: ni un modelo, ni un método, ni un ejemplo, un poco de aire puro, una corriente de aire fresco, incluso cuando dicha corriente venía del Flore, un intelectual que modificaba de forma singular la posición del intelectual. Por eso es totalmente estúpido preguntarse si Sartre es el comienzo o el final de algo.

Como todas las cosas y personas creadoras, está en el medio, crece por el medio. De todas formas, en esa época yo no me sentía atraído ni por la fenomenología ni por el existencialismo, y aunque no sabría explicar verdaderamente por qué, lo cierto es que cuando llegamos a él ya era historia: demasiado método, demasiada imitación, demasiado comentario e interpretación, salvo Sartre. (G. Deleuze, y C. Parnet: 1980; 6-17).

Me propongo rastrear las posibles aproximaciones entre Sartre y Foucault o Deleuze, entendiendo que no se trata sino de rescatar algunos elementos que constituirían un cierto aire de familia más allá de los evidentes y notables desacuerdos. Y partiendo de la consideración que dicho aire de familia no se produce entre Sartre y la generación siguiente, sino, estrictamente, entre Foucault y Deleuze y algunas propuestas sartreanas producidas en algún momento de su dilatada aventura intelectual ${ }^{2}$.

2 El presupuesto de tal advertencia se basa en la consideración de las fuertes rupturas del pensamiento sartreano. He desarrollado dicha evolución en J.-P. Sartre: la pasión de la libertad, Barcelona, Ed. Bellaterra, 2004. 


\section{La inquietud de sí en Foucault y el proyecto sartreano}

Puede reconstruirse con facilidad el desencuentro foucaultiano con Sartre. Si bien no existe una taxativa confrontación en los más importantes textos teóricos, la consideración de Foucault del pensamiento sartreano surge en numerosas entrevistas como si fuera necesario en todo caso remarcar lo que le separa del maestro. Sabemos cuáles con los aspectos de la divergencia. Por un lado, la fuerte descreencia foucaultiana en la perspectiva humanista. Por otra parte, la consideración de la inconveniencia del pensamiento de la Totalización, y, final y esencialmente, el mantenimiento sartreano de un Yo o cogito reflexivo cargado con las marcas de las transparencia y la soberanía: una y otra vez insistirá Foucault en el extremado disgusto que le produce la filosofía del sujeto cuyo representante contemporáneo más conocido es Sartre.

Y, sin embargo, el tono crítico se apacigua a lo largo de la década de los 70 . Interrogado por C. Nemoto sobre el cambio de la función del intelectual replicará de inmediato que nunca tuvo la intención de criticar a Sartre. Similar respeto, que no oculta la distancia teórica, se manifiesta, no obstante, meses más tarde en octubre de 1978 - en la entrevista concedida a Playmen cuando, preguntado sobre si se considera el lógico sucesor de Sartre, advierte Foucault que «Sartre no tiene sucesores, exactamente como no tengo predecesores. Su tipo de intelectualismo es extremadamente raro y personal.»(M. Foucault:1999:531). Pero es necesario prestar atención a un breve comentario que nos ayudará a avanzar. Foucault es entrevistado a propósito del proyecto ético que parece iniciarse con la publicación de La volonté du savoir. H. Dreyfus y P. Rabinow sugieren en un momento que el mismo no dista mucho del existencialismo sartreano. Responde Foucault:

Desde mi punto de vista, y al margen de la divergencia aludida, parece indudable que se dibuja una sintonía básica y fundamental: aceptación de la idea común del yo como algo que no es dado, vinculación práctica del hacerse a uno mismo con la creatividad —y no con la autenticidad—. ¿Qué ha ocurrido? Precisaré dos aspectos: por un lado, que Foucault, al abordar la problemática ética, facilita el posible diálogo con Sartre, ${ }^{3}$ por otra parte, que tal aproximación es fructífera al

3 Dejo a un lado la espinosa cuestión relativa a la periodización de la obra foucaultiana. M. Poster se ha referido a tres momentos: uno centrado en el proyecto arqueológico - hasta 1960 — otro preocupado por la genealogía — hacia 1970 — y, finalmente, el propiamente 
operar sobre un especial momento sartreano, precisamente ése en el que la presencia de Nietzsche es determinante para la configuración de su pensamiento ${ }^{4}$.

Pues bien, entiendo que el proyecto ético foucaultiano está limitado por tres inquietudes esenciales. La primera restaura la analítica de las estrategias del Poder, cuya taxativa referencia se diluye para dejar paso al más conflictivo y expreso término de gubernamentalidad. Foucault desarrolla el asunto a partir de 1977, entendiendo en primera instancia, como se acaba de sugerir, que la gubernamentalidad refiere el desarrollo estratégico del poder diseminado. Desde tal perspectiva aborda su renovada analítica: instituciones, procedimientos, análisis, reflexiones, cálculos y tácticas que apuntan a la legitimación de una soberanía disciplinar que sustituye a los viejos dispositivos( Foucault:1999; 195197). Ahora bien, tal análisis resultaría insuficiente de marginar el movimiento de la potencia adversa que dificulta la proyección biopolítica, pues Foucault remarca, frente a la gubernamentalización del Estado, la exigencia de la gubernamentalidad de sí, de uno mismo, amparada por el reto del ethos ilustrado que se magnifica a partir de la vivencia de la muerte de Dios.

Así, Foucault acepta la exigencia teórica de centrar el cuidado de sí mismo — eje de la gubernamentalidad de uno mismo- como inquietud ética. Al respecto Schmid realiza un certero comentario:

...el concepto clave sobre el que va a girar este desplazamiento va a ser para Foucault la cuestión del gobierno. En lugar de dejarse gobernar, en la ética del

ético — hacia 1980—, «Foucault and the problem of Self-Constitution», en J. Caputo, y M. Yount: Foucault and the critiques of Institutions, The Pennsylvania State Uv. Press, 1993, p. ; por su parte, W. Schmid, a la hora de referir las estrategias de fundamentación de la propuesta foucaultiana, apunta a las pretensiones arqueológica, agonal, histórica, actual y estética, que bien podrían ser cinco momentos, más o menos conflictivos entre ellos mismos, de su aventura: En busca de un nuevo arte de vivir, Valencia, Pre-textos, 2002, p. 33. Perspicaz y polémico el comentario de P. Hadot cuando, refiriéndose a la entrevista concedida a Dreyfus y Rabinow, comenta que la misma «met bien en valeur, lui aussi, cette esthétique de l'existence qui fut pour Foucault sa dernière conception de la philosophie, qui correspond d'ailleurs, trés probablement, à la philosophie qu'il a concrètement pratiquée tuoute sa vie», Exercices spirituels et philosphie antique, Paris, Albin Michel, 2002, pp. 307-308.

${ }_{4}$ Foucault conoce esta presencia de Nietzsche en Sartre: de ello deja constancia en un texto publicado en Telos, primavera de 1983, Dits et écrits, IV, p. 444. La influencia de Nietzsche en Sartre ha comenzado a ser reconocida. Cfr., por ejemplo, J-F. Louette: Sartre contre Nietzsche, Grenoble. Univ. de Grenoble, 1996, o B-H. Lévy: El siglo de Sartre, Barcelona, Ediciones B, 2000, pp. 147 y ss. 
individuo se trata de gobernarse a sí mismo. De este modo, la ética se preocupa de que las relaciones de poder no lleguen a solidificarse como situaciones de dominio; en esa medida, va a desempeñar un papel importante dentro del juego del poder. La nueva fundamentación de la ética del arte de vivir va a implicar así el desempeño de la exigencia ilustrada de aprender a conducirse a sí mismo y de no abandonar en manos de otros el propio cuidado de sî" (Schmid:2001; 206).

Amparándose en numerosas referencias - del platonismo hasta Séneca, Marco Aurelio o Epicteto-, Foucault vino a situar le souci de soi como el exhaustivo ejercicio para confirmar la gubernamentalidad de uno mismo frente o al margen de la renovada estrategia del Estado. El aumento de la cultura helenística y romana, la importancia de cuidarse a símismo es un cambio filosófico importante. Foucault asume la recomendación helenístico-romana, ese horizonte ampliado que está caracterizado por un fenómeno de alcance histórico bastante duradero, pero que conoció en aquel momento su apogeo: el desarrollo de lo que podríamos llamar un cultivo de sí, en el que se intensificaron y valorizaron las relaciones de uno consigo mismo.

Foucault asume la recomendación helenístico-romana, ese horizonte ampliado que está caracterizado por un fenómeno de alcance histórico bastante duradero, pero que conoció en aquel momento su apogeo: el desarrollo de lo que podríamos llamar un cultivo de sí, en el que se intensificaron y valorizaron las relaciones consigo mismo. Y tal aproximación fija, obviamente, la inquietud política foucaultiana a lo largo de la década del 70: se trata de formalizar la intemperancia frente a la gubernamentalización del Estado. A este exceso - en tanto es situarse más allá de lo normalizado- le denominará Foucault obra de arte: la ética es estética de la existencia, prodigiosa conversión de le souci de soi en exhibición de la subjetividad constituyente: « reconoce las técnicas para una penetración más profunda de la normalización y mayores posibilidades de transgresión de estos límites. Este eje de la subjetividad se refiere al conjunto de las prácticas que realizamos en nosotros mismos, y para la ética de Foucault es esencialmente un modo de auto-formación, en la manera en que nuestra libertad es condicionada“ la ética de Foucault es una ética fuerte de auto-desarrollo como un objeto de arte: por su autonomía. La confrontación de la ética del souci de soi deviene en ese aparente e inicial individualismo moral que Schmid subrayaba de forma rotunda:

...cuando Foucault habla de ética, hay que comprenderla en los términos de una ética individual, de una ética entendida como arte de vivir (...) Una moral, en 
suma, que ha de ser reflejo de reflexión partiendo de las categorías de arte de vivir, de la estilística de la existencia y de la conducción de sí (Schmid,2001: 33).

Es indudable que tal posicionamiento es de origen nietzscheano. Pues bien, ¿por qué entonces el propio Schmid ha indicado que el intento foucaultiano de fundar de nuevo la ética parte de una experiencia existencialista y estructuralista? Entiendo que existen varios puntos de confluencia entre la propuesta que Foucault empieza a consolidar en los años 70 y un momento sartreano.

Desde luego, es irrebatible que Sartre, enfrentado a la duplicación husserliana — asunto que hemos esbozado con anterioridad — facilita la recepción del Hegel kojeviano, la lectura peculiar de Marx y la permanencia oculta de Nietzsche, apostantes estos últimos, según la peculiar irrupción de unos y otros en Francia. La proyección ética comprendida como una irreductible dimensión existencial, resuena en la aventura de Foucault a partir de 1970. Y, si existe algún punto de intersección sartreano-foucaultiana, todo lo indirecta que se quiera, éste se precisaría en la contaminación o proximidad teórica que la noción de cuidado de sí evidencia de la noción sartreana de proyecto. Se puede recordar al respecto dos breves fragmentos de El ser y la nada. En el primero de ellos, Sartre apunta que: «He seleccionado constantemente y nunca puede ser tan legítimo, de lo contrario caería en la existencia pura y simple en-sí. La necesidad para elegir constantemente se convierte en uno con la búsqueda continua del yo. Pero precisamente porque es una elección, esa elección es en la medida en que se produce, generalmente significa más posibilidades de elección como sea posible «(Sartre: 1943:560).

La apertura esencial del proyecto sartreano implica la consideración de la existencia como una construcción autosuficiente que se presentifica en la concepción foucaultiana de la ética como arte de vivir asentado en el cuidado de sí. Sugiero que la dimensión del proyecto sartreano encuentra complementaridad con la concepción de una ética que sitúa la existencia como configuración de una obra de arte. No son precisas las críticas de Foucault a los análisis que Sartre realiza sobre Baudelaire o Flaubert: los presupuestos que limitan la ética fundamentalmente anunciada en el tercer volumen de la Histoire de la sexualité, esto es, la muerte de Dios y el atrévete a pensar orientan la actividad y proyección de los escritores aludidos. Ahora bien, ¿no es cierto que la noción de proyecto apunta a la autenticidad como valor, tal y como, por otra parte, señalaba Foucault para remarcar su distanciamiento del 
existencialismo sartreano? ${ }^{5}$ Conviene ser precavidos al respecto, pues a lo que asistimos en El Ser y la nada es a una copresencia difícilmente articulable entre la necesidad de asentar el compromiso social hacia el que Sartre se orienta y la admiración no diluida hacia la filosofía nietzscheana. Situados en tal perspectiva, el proyecto sartreano y la obra de arte como finalidad ética en Foucault presentan indudables correspondencias - y no conviene olvidar que Baudelaire y Flaubert llaman la atención, precisamente, en los momentos sartreanos más alejados de cualquier pretensión totalizadora-.

Y, desde mi punto de vista, existe un segundo aspecto en el que el diálogo es evidente, aunque sea de otra tipología. Como se ha señalado previamente y subrayando la valoración llevada a cabo por Schmid, la ética foucaultiana es esencialmente individualista. Tal carácter asentaba la crítica de Hardt y Negri: « lo que finalmente Foucault no fue capaz de comprender fue la dinámica real de la producción que tiene lugar en la sociedad biopolítica».(M. Hardt, y A. Negri, :2002; 42.). Ahora bien, que la aventura teórica de Foucault trasmita la incomodidad que le producía abordar el capítulo pertinente de la estrategia comunitaria, limitándose tan apenas a reconocer la pertinencia del principio liberal de que nos gobiernan siempre demasiado no significa que el Cuidado de sí carezca de implicaciones colectivas o sociales ${ }^{6}$. En efecto, la consideración del fundamental capítulo II de Le souci de soi pone de relieve que el individualismo que transmiten los numerosos textos de referencia, ese imperativo que requiere la relación consigo mismo, es indisoluble de una socialización: «tocamos aquí uno de los puntos más importantes de esta actividad consagrada a uno mismo: constituye, no un ejercicio de la soledad, sino una verdadera práctica social»(Foucault: 1987; 51). Parecerá claro que la relación entre le souci de soi y la socialización del mismo está aquejada de una grave inconveniencia, pues el proceso de la práctica social está determinado por un fuerte grado de aletoriedad que recuerda, obviamente, la azarosidad blanchotiana. Tan sólo la contaminación

5 Una interesante y válida aproximación al asunto ha sido llevada a cabo por A. Gorz, Fragments sur authenticité et valeur dans la première philosophie de Sartre, Les temps modernes, 531-533, 1990.

6 Lo cierto es que Foucault entiende la dimensión socio-política de le souci de soi, aunque su insistencia en una ética entendida como estética de la existencia impida la resolución. Entiendo que existe una muy fuerte confrontación entre la propuesta ética confirmada por le souci de soi y la dimensión social —en la perspectiva foucaultiana. Tan sólo parece pertinente la confianza en la aletoriedad que vincule la concordia entre el despliegue de lo individualy el interés colectivo. 
del imperativo ético augura escasas y lejanas posibilidades frente a la gubernamentalización del Estado. Así, Foucault se sitúa en un plano de individualismo ético, aunque entendiendo que es propio de le souci de soi la proyección social.

La propuesta foucaultiana merecería críticas debido a su supuesta inoperancia política. Como apuntaba, por ejemplo, R. Rochlitz. ¡Exactamente la misma crítica que traslada ¿Existentialisme ou marxisme? de Lukács! Pero sucede que Sartre y Foucault operan sobre una planilla semejante. Como Foucault, el Sartre de los años 40, y la posterior reaparición de lo que limita la óptica lectora a la que nos hemos referido con anterioridad, es incapaz de articular el carácter individual del proyecto y una socialización de la finalidad individual que no puede representarse sino como trascendental político, derivación que, como puede comprenderse, ni Sartre ni Foucault pueden asumir. Sartre derivará hacia la tesis de la mediación partidaria. Pero éste es ya otro asunto. ¿Y Foucault? Quizás se limite a encarnar la figura del chevalier de l'autonomie, como indicara Rorty alimentada del hiperactivismo pesimista que el propio Foucault reconociera como seña de identidad de su presencia política. Sartre reaparece en su obra como apostante a favor de la autoconstitución subjetiva: se trata del Sartre de La trascendencia del Ego, de La náusea, y más allá de su aproximación al proyecto comunista, del tratado sobre Flaubert.

Deleuze está en el horizonte... El análisis paciente y frío de las estructuras es desplazado por la consideración de los despliegues, de los desplazamientos, de las insumisiones. Foucault certifica algo esencial cuando redacta el prólogo para la edición inglesa de El Antiedipo: “...se trata de un libro de ética, el primer libro de ética que hemos escrito en Francia en muchos años". ( M. Foucault, Dits et écrits, III, p. 134. ).

\section{Autoconstitución subjetiva en Deleuze y la Irreductibilidad existencial en Sartre}

En 1989 Deleuze organizado su trabajo de 11 encabezados temáticos, comenzando con «A partir de Hume a Bergson». Tres de estos primeros textos tienen que ver principalmente con Sartre. Los pocos comentaristas que se han escrito sobre estos textos, en consonancia con la influencia en Deleuze. François Dosse, por ejemplo, en su reciente biografía de Deleuze y Guattari, denuncia la inclinación

sartreana de estos artículos como un enamoramiento adolescente. Comenta que 
Deleuze desautorizó a Sartre poco después de haber escrito estos textos, y se pone en marcha en un "camino completamente diferente «. (Dosse: 119-20).

No parece, sin embargo, que Deleuze se haya embarcado por completo en diferentes rutas de acceso. Al igual que muchas personas sólo después de la guerra Deleuze quedó impresionado por el estilo de Sartre. Él escribió que no sólo admirar Sartre por su "Genio de la totalización, sino también porque él sabía cómo inventar algo nuevo.» Con esta afirmación, aparentemente Deleuze quiere significar que Sartre sabía cómo crear eventos. Por esta razón escribió: «Las primeras actuaciones de Las moscas, la publicación de El ser y la nada [...] la conferencia Existencialismo y humanismo - estos trabajos eran la forma en que se ha desarrollo, después de largas noches, la identidad del pensamiento y la libertad. «El alaba a Sartre por ser, como Nietzsche, un «pensador privado», hablando en su «propio nombre,» (Deleuze, 1988: 77 - 8). Parece haber sido un ejemplo de cómo uno puede ser también un intelectual, para Deleuze, una especie de héroe un precursor de su pensamiento. Esto es, al menos, la tesis generalmente aceptada entre los académicos.

Esta conclusión no es sorprendente dado el hecho de que Deleuze siempre sostuvo que no sentía la proximidad a la fenomenología ni al existencialismo. En Deleuze, la única filosofía de Sartre ampliamente reconocida, radica en la noción de "presubjetivo" que es un campo trascendental que Deleuze descubre en $L a$ trascendencia del Ego, y que le lleva a adoptar su ontología de la immanencia.

“Triste generacione sin maestros”,así se inician esas páginas reveladoras recogidas en $L$ île déserte y dedicadas a Sartre. Más adelante, y después de haber subrayado algunos aspectos — a los que de inmediato me referiré—, subraya Deleuze: "Esta es la razón por la que Sartre sigue siendo nuestro maestro" (G. Deleuze: 2002; 45).

¿Por qué? ¿A qué se refiere, qué homenajea Deleuze? Es indudable que una nueva forma de hacer filosofía, no centrada no tan sólo en el desarrollo sino en nuevo estilo, una nueva forma agresiva y polémica de plantear problemas, tampoco es sólo en que Sartre representara la figura de pensador privado o que encarnara la figura del intelectual prestigioso para dictar oracularmente, esa estirpe magnificada por Zola o Rolland. Quisiera recordar tres aspectos de suficiente calado, apuntados en Il a été mon maître. Entiendo que Deleuze deja constancia de tres advertencias sartreanas que orientarán su obra - téngase en cuenta que, cuando el artículo aparece en Arts en noviembre de 1964, Deleuze ha publicado 
artículos de marcada orientación técnica, si bien ya, por ejemplo, ha dedicado atención al existencialismo (Sartre, Merleau-Ponty, G. Marcel), su interés comienza a ensalzar la función de lo no-representativo (Sacher-Masoch, Kafka, Ponge, R. Roussel) y está sumido en la problemática de Différence et répétition (1968)-.

¿Aqué advertencias nos referimos? Escribe Deleuze «Toda su filosofía fue parte de un movimiento especulativo de acuerdo a la noción de representación, el orden de la representación: la filosofía cambio de sede, dejando el ámbito de la Sentencia a establecerse en el mundo más colorido los efectos perjudiciales, la sub-representación» ${ }^{7}$. Es, como comentaremos brevemente de inmediato, un inevitable y primer punto de intersección: lo perjudicial, lo sub-representante conceden prioridad a la movilidad en tanto efecto de la plenitud ontológica de la inmanencia y, en tal sentido, puede comprenderse con facilidad que las sugerencias de la escritura poética aparecen como señales orientativas más esenciales que las aportadas por la opacidad autosuficiente de la filosofía.

Es incuestionable que tal reivindicación de la abolición de la función teórica de la representación abonará una de las trayectorias intelectuales de Deleuze hasta Crítica y clínica - como lo es que alcanza fijación teórica en la propuesta de la diferencia sin concepto, vertebral en la obra del 68, y en la paralela reivindicación del simulacro denostado por Platón. Lo que se condena en el simulacro es el estado de las diferencias libres oceánicas, de las distribuciones nómadas, de las anarquías coronadas, toda la malignidad que cuestiona tanto la noción de modelo como la de copia, apunta Deleuze para remarcar la urgencia de eludir la representación que atosiga la realidad de lo que aparece o, de inmediato, la potencia del deseo. Entiendo que: lo perjudicial, lo subrepresentante es, en el horizonte sartreano, esa dirección que constata la irreductibilidad del existente en su juego situacional-proyectivo que se remarca con fuerza en El Ser y la Nada y que taxativamente aceptará la relevancia de teoría de la libertad, que se ha limitado mediante la formación de situaciones. En el psicoanálisis existencial que abarca la elección de base de un individuo en su vida real aludamos a un segundo punto de intersección sartreano-deleuziano. En el breve texto que estamos considerando como móvil para la presentificación de un cierto aire de familia, Deleuze recuerda: «Sartre fue capaz de reunir un pensamiento único, ¿cuáles son las condiciones de agregación: uno en la

7 Ibid., pp. 110-111. 
imaginación política, la sexualidad, el inconsciente, se reunirá en los derechos humanos de $\operatorname{todos}^{8} \gg$.

\section{A modo de conclusión}

Dejemos a lado la exactitud de lo que Deleuze denomina "totalisation”, pues lo importante es reconocer una proximidad por lo que se refiere a la quiebra con la unicidad de una marca antropológica que, determinando las subjetividades, permitiera representarse a éstas como sujetos. Sartre ha comenzado desde los años 40 a remarcar la diversidad de los efectos constituyentes de la subjetividad que profundizan una trayectoria paralela a la de las ofertas clásicas, tanto en sus aproximaciones a ejemplaridades literario-poéticas —Baudelaire, Genet, por ejemplo-, que ponen de relieve la imposibilidad de categorizar antropológicamente una especie de figura humana modélica, así también en cuanto a intervenciones filosóficas y polémicas — como pueden ser la obra de Sartre Lo imaginario, referida de forma trasversal en el artículo deleuziano del 64, o otra obra también de Sartre: Materialismo y revolución al que Deleuze dedica un breve comentario en 1955 publicado en la Revista filosófica de Francia y el extranjero. Esta forma es deudora de un momento especial de la aventura sartreana y, en consecuencia, no es de extrañar que Deleuze se cobija al amparo del autor de Lo imaginario. Tal tensión se convierte en la columna vertebral de la obra deleuziana, como ha observado Negri al subrayar:

...que hay pues esta otra manera de pensar que se quiere profundamente antiplatónica, en la que el sentido del acontecimiento y de la singularidad, de la haecceidad se hacen centrales. El cuadro que tenemos ante nosotros es el mismo al que antes me refería, es decir, esta imagen postmoderna de lo real que es animada por esa irreductibilidad de los procesos de subjetivización» (Negri; 1994: 19).

Es de importancia la obra de 1940 porque se puede ver desde la misma condiciona una tercera área de intersección. Es preciso recordar los últimos párrafos del artículo emocionado de Deleuze. Habiendo considerado el valor complementario de la "Critique" en relación a " $L$ 'être", introduce Deleuze un inquietante comentario. Se refiere a «Mi amigo Pedro-que-nunca estuvo allí « (Negri; 1994: 19). y, líneas después, reitera la misma instancia. ¿Se nos dice algo más de lo que se dice? Es obvio para los estudiosos sartreanos, pues Lo imaginario comienza

8 Ibid., p. 111. 
a desarrollarse sobre la base de la imagen de mi-amigo-Pedro-que-no-está. ¿Qué significa esto?: que la conciencia está abocada esencialmente a una intranquilidad constitutiva — derivada de la posibilidad de que la imagen de mi-amigo-Pedro que- no-está sea un fiasco- y que mi conciencia está abierta a un juego que conjuga realidad inmediata y apertura constitutiva. Tal será la esencia del deseo en tanto efecto de la inmanencia que se revela como diferencia sin concepto: el deseo deleuziano, como el proyecto sartreano sustentado en la conciencia imaginante, es anuncio de un hacerse en el vacío o, si se quiere, en lo-que-noestá. La concepción de la diferencia como lo que difiere de la negación sin que se oponga a ésta, estableciéndose como tal, marca una aproximación incuestionable a la consideración sartreana de lo imaginario y, desde luego, a la noción de proyecto — si bien, ésta, tal y como se desarrolla en la obra del 43 y en la aproximación a algunas ejemplaridades estético-literarias se puede establecer una relación unívoca entre afirmación y negación.

Es preciso notar que tales son las tres áreas de intersección sartreano-deleuziana. Pero, a pesar de que Deleuze reconozca, a propósito, la continuidad entre las obras filosóficas de Sartre de 1943 y 1960, se trata de una conjugación tan especial como la referida a propósito de Foucault: esto es, se trata de un encuentro entre Deleuze y el Sartre lector cercano y singular de las presencias que se han evocado al comienzo y que mantienen su vigencia, más o menos solapada, a lo largo de toda la obra sartreana. Es decir, Deleuze se encuentra con el Sartre nietzscheano, con el Husserl anterior a la duplicación del yo, con la dialéctica sin Hegel reivindicada por Kojève, con el Marx humanista, en suma, con el Sartre que limita la subjetividad como proyección a partir de una vaciedad constitutiva que comienza a ser en la situación irreductible del existente, o, si se quiere, que comprende la existencia como creación-proyecto.

Un cierto aire de familia... Es lo que se conforma a partir de los años sesenta entre Sartre y los sucesores en el teatro filosófico francés. Quizás predominara antes del reencuentro la complejidad de esa estrategia que determina la sucesión de los modelos y de las temáticas, a la que, centrándose en el horizonte literarioartístico, se ha referido Bourdieu. Ciertamente, el estructuralismo no se sentía cómodo ante el esencial subrayado sartreano en la potencia de la subjetividad, ante su consideración de la situación y, por ende, ante la propuesta del proyecto como dimensión ética asentada en la subjetividad misma. Pero son tales aspectos los que, finalmente, terminan por condicionar y determinar el encuentro iniciado a lo largo de los años sesenta. 
No es de extrañar que el Foucault menos estructuralista — en el caso de que sea legítimo achacársele tal inscripción — terminara por evidenciar la contaminación sartreana en el momento en que sus intereses se orientan hacia la problemática ética y el individualismo que entiende el arte de vivir como estética de la existencia sustentada en le souci de soi, y que Deleuze admitiera su seducción por esa reivindicación sartreana de las ejemplaridades estético-literarias en las que la ética-creación se revela y, a la postre, por la actitud ética comprendida como presencia deseante y creativa. Culminó, así, una larga travesía marcada por un inicial distanciamiento y un epílogo venturoso que diseña un nuevo marco de la problematización filosófica.

\section{Bibliografía}

NEGRI, A .Deleuze y la política, en El Archipiélago, no 17, otoño de 1994.

COHEN-SOLAL, A. Sartre, Paris, Gallimard, 1985, p. 139.

SARTRE, J.-P. La trascendencia del Ego, Buenos Aires, Calden, 1968.

SARTRE, J.-P. Crítica de la razón dialéctica, I, 1, Buenos Aires, Losada 1987.

SARTRE, J.-P. «Paul Nizan», en Literatura y arte, Situaciones IV, Buenos Aires, Losada 1986.

SARTRE, J.-P. «Sartre répond», L’Arc, nº 30, p. 88.

A. KOJÈVE, La dialéctica del amo y del esclavo en Hegel, Buenos Aires, La pléyade, 1971.

ZOURABICHVILI, F Deleuze, Buenos Aires, Amorrortu/editores 2007.

GROSS, F. Michel Foucault, Buenos Aires, Amorrortu/editores 2007.

DOSSE, F. Historia del estructuralismo, 1, Madrid, Akal, 2004.

DELEUZE, G.Diferencia y repetición, Buenos Aires, Amorrortu/editores 2006.

DELEUZE, G. «Il a été mon maître», en $L$ île déserte et autres textes, Paris, Minuit, 2002.

DELEUZE, G. Diferencia y repetición, Gijón, Júcar, 1988.

DELEUZE, G. Leouvel Observateur, 1619, 16 November 1995..http:// mail.architexturez.net/+/Deleuze-Guattari- L/archive/msg23820.shtml

DELEUZE, G. y C. PARNET, Diálogos, Valencia, Pre-textos, 1980.

CANGUILHEM, G. en Magazine littéraire, no 293, noviembre de 1991.

HARDT, y A. NEGRI, Imperio, Barcelona, Paidós, 2002, p. 42.

FOUCAULT, M. Las palabras y las cosas, Buenos Aires, Siglo XXI, 2002. 
FOUCAULT, M. La inquietud de sí, Madrid, Siglo XXI, 1987.

FOUCAULT, M. Dits et écrits, III, 1996.

FOUCAULT, M. «La gubernamentalidad», en Estética, ética, hermenéutica, Barcelona, Paidós, 1999.

W. SCHMID, En busca de un nuevo arte de vivir, 2001.

A. MARINO, «L'Analytique de la subjectivité de M. Foucault. Du souci de soi à l'ethos philosophique», en M. Foucault. Trayectoires au coeur du présent, Paris, L'Harmattan, 1988 Sartre, L'être et le néant, Paris, Gallimard, 1943.

ERIBON, Didier, Entretien avec Gilles Deleuze, 'Le « Je me souviens » de Gilles [Accessed Mar. 24, 2009] Dosse, François, Gilles Deleuze et Félix Guattari: Biographie croisée (Paris: Éditions La Découverte, 2007). 